\title{
Application of Micro Lesson in Courses of Pharmacy Specialty
}

\author{
Liping $\mathrm{An}^{1, \mathrm{a}}$, Lifeng $\mathrm{MiaO}^{2, \mathrm{~b}}$, Guangyu $\mathrm{Xu}^{1, \mathrm{c}_{*}}$ \\ ${ }^{1}$ College of Pharmacy, Beihua University, Jilin city, Jilin, China \\ ${ }^{2}$ The first clinical hospital of Beihua University, Jilin city, Jilin, China

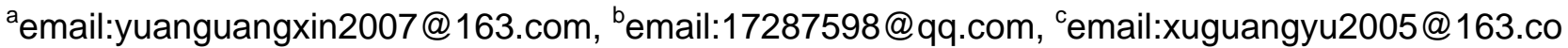

$\mathrm{m}$

* Corresponding Author: Guangyu Xu

Key Words: Micro Lesson; Pharmacy Specialty; Network Teaching

\begin{abstract}
The application of inquiry teaching is an inevitable trend to adapt to the reform and development of higher education, and how to better implement inquiry teaching in the teaching of pharmacy courses is an important issue that we have to face in the practice of pharmacy teaching modes currently. In this paper, how to better apply teaching methods of micro lesson in the inquiry teaching practice of pharmacy specialty courses are discussed for improving the effects of inquiry teaching in this paper. The application of micro lesson in the inquiry teaching of pharmaceutical courses may contribute to the cultivation of students' autonomous learning and innovation ability. The method can not only improve the effect of inquiry teaching in the classroom teaching, but also make the students' inquiry learning extend from the classroom teaching to the students' learning after class. With its wide application in the teaching of colleges and universities, micro lesson, as a new teaching technology, will promote the development of pharmacy teaching reform and the cultivation of students' innovation ability.
\end{abstract}

\section{Introduction}

In the era of web 2.0, teaching activity has been not only a process limited in the classroom. In contrast to the traditional teaching mode, network teaching methods are characterized by the learning autonomy that is not subject to the constraint of time and space, and the open sources that cannot be restricted by students' ages, profession and intercollegiate relation. With the progress of the times, network teaching has been no longer simply a presentation of knowledge based on data, but has more and more clearly shown some characteristics such as flexibility and individual participation [1]. Micro lesson teaching, as a new mode of network teaching methods, has highlighted its unique advantages with its features, such as diverse forms, easy and simple preparation, strong pertinence, and click-to-run. During the micro lesson teaching, the information taught by the teachers includes not only the body language, and tone and expression, but also the integration of dynamic processes of some experimental manipulations, writing on the blackboard, and PPT courseware [2]. This immersive feeling has attracted a great attention of many teaching workers and learners. Because the micro lesson can be prepared, presented, and used for learning and exchanging through a variety of mobile terminals of smart phones, tablet personal computer, etc., it has been accepted by more and more students and teachers. The application of inquiry teaching is an inevitable trend to adapt to the reform and development of higher education, so that how to better implement inquiry teaching has become an important issue that we have to face in the 
practice of pharmacy teaching at present. How to better apply teaching methods of micro lesson in the inquiry teaching practice of pharmacy specialty courses are discussed for improving the effects of inquiry teaching in this paper.

\section{Definition of Micro Lesson}

Micro lesson is a teaching mode with episodes of audio or video prepared based on the teaching design ideology, in which audio or video is used as the main carrier to record the whole process of teaching and learning activities centering on a certain knowledge point or teaching link in the process of classroom teaching. Its core contents include micro teaching video, and supporting teaching resources related to the teaching topics, such as micro lesson plans, micro courseware, micro practice, micro reflection, micro reviews, and micro feedback ${ }^{[3]}$. The "micro" of micro lesson has two contents, the first is a micronization of the time and the second is the micronization of knowledge structure. The time micronization means that micro lesson is short and pithy, the contents can be presented online and easy to be browsed, conducive to the students' learning by utilizing their fragmented time; the micronization of knowledge structure refers to the small amount of teaching contents, the highlighted theme, and the independent and refined contents, which is helpful for students to make up for deficiency and take what they need to realize the "personalized" selection of teaching and learning ${ }^{[4]}$.

\section{Problems in the Teaching of Pharmaceutical Courses}

Poor Students' Basic Knowledge, Leading to A Poor Teaching Effect. Pharmacy is a inter discipline subject of biology, chemistry and medicine, and more pharmaceutical, chemical and biological knowledge are involved in the teaching process of pharmacy. However, a considerable number of the students are lack of the knowledge in these areas, so when the students study pharmaceutical issues in the way of independent inquiry, some practical problems often come out, such as poor participation interest, relatively single design scheme after class, and lower team cooperation efficiency, resulting in a poor teaching effect.

Poor Students' Practice and Innovation Ability, Leading to An Implementation of Teaching. In the experiment or the practice in accordance with the independent design of inquiry programs, most students' manipulation is not so skilled, which is primarily because the students themselves are not familiar to the relevant pharmaceutical knowledge essential to the experiment or practice, and not thoughtful for some of the details in their experimental process, except that some processes may be more complex, so they will always encounter many issues beyond their imagination.

\section{Application of Micro Lesson in the Inquiry Teaching Practice of Pharmaceutical Courses}

Pharmacy is a comprehensive subject in which chemical, biological, medical and other knowledge is integrated. An obvious characteristic of pharmaceutical course is practical, and most of them are learned by teaching methods in the combination of theory and experiment courses. In the experiment courses, especially the courses related to chemistry, experimental conditions for them are generally very strict and the teaching implementation is difficult, such as the need to the conditions of high temperature and high pressure, and the use of reagents with high toxicities, or harmful gases and waste liquid that can release volatile toxic substances. Aiming at these characteristics of experiments in the experiment courses, some teaching contents can be made into micro videos and presented through network resources, which may not only give the students an intuitive perception, but also overcome the difficulty of experiment implementation caused by the 
deficient conditions, and at the same time, the risk for the students and teachers to expose to the potential toxicities in the laboratory can be avoided ${ }^{[5]}$. In the experiment course of analytical chemistry and pharmaceutical analysis, analytical instruments, especially large precious instruments, are often used. If the instruments cannot meet the demand of experiment teaching, the related demonstration, operation, methods and principles can be prepared into micro videos to present the experiment course contents to the students, in which the knowledge is explained from multiple angles, and the students can not only increase the perceptual knowledge, but also better understand the instruments used in the experiments. The experiment course of traditional Chinese medicine involves a variety of specimens, such as medicine herbarium, crude drug specimens, plant specimens in solution, identification specimens, plant specimens, and animal specimens of traditional Chinese medicines, which may provide an arena for the micro video resources. The applications of the micro lesson in the teaching practice of pharmacy specialty in our college are discussed here.

Application of Micro Lesson in the Preview before Class. Most of the pharmacy teaching contents involve the knowledge of chemistry, medicine and microbiology, but the foundation of these aspects generally is not so good in the students whose majors are the biology-related specialty, such as pharmaceutical students. Due to this reason, teachers can prepare targeted micro lessons based on the chemical and medical knowledge required for the learning of new knowledge that students are going to learn, and then let the students selectively watch the micro lessons according to their actual situation when they are going to learn a new lesson, to lay a good foundation for the inquiry learning of following new course. For example, the process of infrared detection, a part of the contents in the course of pharmaceutical analysis, can be prepared into a micro lesion for the students to preview it before class.

Application of Micro Lesson in Classroom Teaching. In the classroom teaching practice of pharmacy courses, teachers should actively guide and promote the students to explore, but the excessive use of micro lesson could make students lose the power of inquiry, resulting in a dependence of the students on the micro lesson, so that the teaching contents for micro lesson teaching should be selected when micro lesson is used for pharmacy teaching. The micro lessons should be prepared based on the important and difficult contents, and then uploaded to the corresponding course learning website, so that the students can watch and study them not only in the classroom learning, but also after class. For example, when teachers introduce the sample detection by high performance liquid chromatography, the micro lessons can be used to explore the detection with different chromatographic methods and the effects of different chromatographic methods on the sample testing results.

Application of Micro Lesson in the Knowledge Expansion after Class. Due to differences in the student's own knowledge structure and comprehension ability, their understanding degrees of the same knowledge are very different, and it is impossible for the inquiry learning to be conducted aiming at every student in the classroom teaching. Therefore, teachers can design and prepare the learning auxiliary materials (video teaching, supporting documents, etc.) with expansibility into micro lessons according to the implementation of the classroom teaching and the students' practical ability, to meet the learning of students who have a spare capacity to go on carrying out the inquiry learning in their spare time to continue. For example, after the classroom teaching of high-performance liquid chromatography, the important issues related to fake traditional Chinese medicines or their active ingredients detected by high-performance liquid chromatography in recent years can be introduced to the students, and then the students are guided to use high-performance liquid chromatography to detect certain types of traditional Chinese medicines, in order to make 
them understand the application principle and the objectives to understand related parts of high-performance liquid phase chromatography.

\section{Conclusions}

The application of micro lesson in the inquiry teaching of pharmaceutical courses may contribute to the cultivation of students' autonomous learning and innovation ability. The method can not only improve the effect of inquiry teaching in the classroom teaching, but also make the students' inquiry learning extend from the classroom teaching to the students' learning after class. With its wide application in the teaching of colleges and universities, micro lesson, as a new teaching technology, will promote the development of pharmacy teaching reform and the cultivation of students' innovation ability.

\section{Acknowledgements}

This research work was supported by research and teaching of Beihua University (youth education project) 2014035.

\section{References}

[1] Shieh D. These lectures are gone in 60 seconds[J]. Chronicle of Higher Education, 2009, 55(26): A1,A13.

[2] D.D.Xu, Z.H.Ou, X.P.Bi. Try to carry out micro-teaching in Pharmaceutical Majors [J]. Pharmaceutical Education. 2014( 2) 27-29.

[3] T.S.Hu, M.Y.Huang, M.Li. Three stages of development of the micro-lesson extremely Inspiration [J]. Journal of Distance Education. 2013,4: 36-42.

[4] L.M.Liang, Q.Q.Zeng, B.H.Zhang. Microstructure of Course Design Mode - Based on comparative analysis of domestic and micro courses [J.] Open Education Research. 2013,19( 1) : 65-73.

[5] X.P.Bi, Z.J.Zhao, S.Hu. Network Simulation Teaching Research and Practice of Pharmacy Experiment Curriculum [J]. Preclinical Medical Education. 2011,13( 12) : 1109-1110. 